\title{
Co-Culture as the Novel Approach for Drug Discovery from Marine Environment
}

\author{
Athira Krishnan KA and Keerthi TR* \\ School of Biosciences, Mahatma Gandhi University, India
}

Submission: September 13, 2017; Published: September 22, 2017

*Corresponding author: Keerthi TR, Microbial Biotechnology Laboratory, School of Biosciences, Mahatma Gandhi University, Kottayam, Kerala, India, Email: keerthisureshbabu@gmail.com

\begin{abstract}
Marine ecosystem is the bountiful source of pharmacologically relevant compounds. The enhanced productivity of this ecosystem is contributed mainly by the marine invertebrates. Though there is a serious problem of compound supply from these invertebrates, total synthesis and semi-synthesis efforts of the known compounds has helped us to simplify the problem. Another approach to enhance these compound productions is based on the microbes associated with them. Identification, extraction, genomic mining and co-culture approaches of these microbes will help us to meet the economic feasibility of the active principle or the bioactive metabolite. In this review, we come across the co-culture approaches of drug discovery from the marine environment.
\end{abstract}

Keywords: Co-culture; Mixed fermentation; Marine microbes; secondary metabolites; Quorum sensing; Antibacterial; Cytotoxic

\section{Introduction}

Natural products have various applications ranging from their uses in foods, cosmetics, pigments, medicines, insecticides etc. $60-75 \%$ of new drugs for cancer and infectious diseases reported between 1981-2002 were from natural sources [1]. From 1940s to the end of 2014, 131 (75\%) of the 175 small molecules approved were not synthetic i.e., the belonged to biological macromolecule, unaltered natural product, botanical drug, natural product derivative, mimic of natural product etc. and $85(49 \%)$ among them being natural products or directly derived there from [2].

Marine environment continue to be the treasure house of novel natural products which are potential drug candidates. The variability in thermal, pressure and nutrient ranges in the ocean facilitated extensive specification at all phylogenetic levels from microorganisms to mammals. Many bioactive compounds have been obtained from various marine animals like tunicates, sponges, softcorals, bryozoans, sea slugs and marine microorganisms [3].

Marine derived microbes are promising sources of novel bioactive compounds that are important for drug discovery process. The proportion of active bacteria associated with marine invertebrates (20\%) and sea weeds $(11 \%)$ is higher than that isolated from sea water and sediments (5\%).Bioactive compound production by microorganisms associated with marine invertebrates could be attributed to the competition among them for space and nutrition. Though these bioactive compounds may be important for epibiotic defense of marine invertebrate hosts, they also have significant medical and industrial applications. The involvement of microorganism in the natural product biosynthesis has been evidenced in the case of Dysidea herbacea and Theonella swinhoei.

Lack of ethno medical history and the difficulties involved in the collection of marine organisms have made the research into the use of marine natural products to remain in its infancy. The development of new diving techniques, remote operated machines etc. helped us to meet the difficulties in marine sample collection and during the past decade, over 4200 novel compounds have been isolated from shallow water to $900 \mathrm{~m}$ depths of the sea. The development of high throughput screening (HTS) technology increased the assay speed and the combinatorial chemistry speeded up the drug discovery process [3]. Recent advances in the molecular biology of bacteria and fungi have helped us in understanding the genetic potential of these microbes with respect to their capability of producing chemically diverse compounds. Under the laboratory conditions, many of the biosynthetic genes in microbes remain silent or are not transcribed. Thus we have obtained only a fraction of the real biosynthetic diversity of the compounds of microbial origin and this leads to the bottleneck in drug discovery from microbial sources.

In order to overcome the limitation during fermentation of microbes for bioactive compound production, several approaches are there: 
a. The OSMAC (one strain many compound) approach- In order to maximize the diversity of compounds produced, promising strains are cultured in a variety of media and under different culture regimes

b. Epigenetic modifications- To modulate histones or DNA for initiating the transcription of the silent genes, microorganisms are treated with epigenetic modifiers such as histone deacetylase inhibitors or DNA methyl transferase inhibitors. This modulation may lead to the accumulation of new compounds.

c. A third approach is co-culture- In this microbes always coexist within complex microbial communities [4].

\section{Co-culture}

Co-cultivation (also called mixed fermentation) of two or more different microorganisms tries to mimic the complex microbial habitat in nature where they coexist. Due to the competition for limited resource and antagonism, these microbial communities produce bioactive secondary metabolite as part of defense. The competition and antagonism among these microorganisms is believed to activate the biosynthetic genes that remain silent under luxurious culture conditions. Thus these silent genes are transcribed under the induced stress conditions in co-culture and in turn lead to accumulation of cryptic compounds that are not detected in axenic cultures of the producing strain. The coculture of isolates from the same source or organism, may lead to enhanced production of constitutively present compounds in the organism. Thus the co-cultivation paves the way for increasing the chemical diversity of microbes from both the marine and terrestrial habitats.

Co-culturing is a powerful experimental tool for either enhancing the production of constitutively present compounds and/or for inducing silent gene clusters. It is a viable experimental approach for enhancing the chemical diversity of microorganisms when grown in vitro. In co-culture, induction of competition and stress lead to increased production of novel compounds that are not detected in pure cultures. Co-culture systems have been used to study natural interactions between populations, for improving cultivation success for certain populations and for establishing synthetic interactions between populations $[5,6]$.

Bacterial cells show cell-cell communication in presence of other bacteria with their auto inducers. This aid the bacteria to sense a critical cell mass ad in response activate or repress target genes. Thus quorum sensing and quenching mysteries of marine derived microorganisms could be unraveled with these studies. Co-culture of fungus Aspergillus nidulans challenged by Streptomyces rapamycinicus first time provided the cue for the molecular basis of induction of silent fungal biosynthetic gene clusters $[7,8]$.

Three major strategies of co-culture studies are:

a. Co-cultivation of different fungi
b. Co-cultivation of fungi with bacteria
c. Co-cultivation of different bacteria

\section{Co-cultivation of marine derived microorganisms}

Co-culture of two marine actinomycetes ANAM-5 an AIAH10 in yeast extract-glucose media enhanced antifungal and cytotoxic activities along with production of one new compound [9]. Here the induction of new compound production may be due to the interaction between the two cultures. Marine brown alga Rosenviagea sp. derived fungus Pestalotia sp. Cocultures with marine derived unidentified Gram negative bacteria of the genus Thalassopia (CNJ-328) produced chlorinated prenylsecoanthraquinone, pestalone which possessed antibacterial activity against methicillin resistant Staphylococcus aureus (MRSA) and vancomycin resistant Enterococcus faecium and also exhibited cytotoxicity in National Cancer Institute's 60 human cell line screens [10].

Table 1: Marine-derived microorganisms co-culture and compounds reported.

\begin{tabular}{|c|c|}
\hline Co-Cultivated Microorganisms & Compounds reported \\
\hline Aspergillus sp. ,Aspergillus sp. & $\begin{array}{c}\text { Aspergicin, Neoaspergillic acid, } \\
\text { Ergosterol }\end{array}$ \\
\hline $\begin{array}{l}\text { Unidentified fungus, } \\
\text { Unidentified fungus }\end{array}$ & $\begin{array}{c}\text { 8-Hydroxy-3-methyl-9-oxo- } \\
\text { 9H-xanthene-1-carboxylicacid } \\
\text { methylether }\end{array}$ \\
\hline $\begin{array}{l}\text { Unidentified fungus, } \\
\text { Unidentified fungus }\end{array}$ & $\begin{array}{l}\text { Marinamide, Marinamide } \\
\text { methylether }\end{array}$ \\
\hline $\begin{array}{l}\text { Pestalotia sp., Unidentified } \\
\text { bacterium }\end{array}$ & Pestalone \\
\hline Libertella sp. and Thalassopia sp & Libertellenones A-D \\
\hline $\begin{array}{c}\text { Emericella sp, Salinospora } \\
\text { arenicola }\end{array}$ & $\begin{array}{c}\text { Emericellamide A, Emericellamide } \\
\text { B }\end{array}$ \\
\hline $\begin{array}{c}\text { Aspergillus } \\
\text { fumigatus,Sphingomonas sp. }\end{array}$ & Glionitrin A \\
\hline $\begin{array}{c}\text { B. thuringensis } B \text {, megaterium } \\
\text { S, sciuri }\end{array}$ & Indole, Phe-Pro diketopiperazines \\
\hline $\begin{array}{c}\text { Streptomyces tenjimariensis, } 12 \\
\text { unidentified bacteria }\end{array}$ & Istamycins \\
\hline $\begin{array}{l}\text { Penicillium sp. WC-29-5, } \\
\text { Streptomyces fradiae }\end{array}$ & $\begin{array}{c}\text { Deoxyfunicone; 1,3,8-trihydroxy- } \\
\text { 6-methylxanthen-9-one; } \\
\text { 9R, 14S-epoxy-11- } \\
\text { deoxyfunicone;9S,14R-epoxy-11- } \\
\text { deoxyfunicone }\end{array}$ \\
\hline $\begin{array}{c}\text { Aspergillus fumigatus, } \\
\text { Streptomyces leeuwenhoekii } \mathrm{C} 34\end{array}$ & Luteoride D, \\
\hline $\begin{array}{c}\text { Aspergillus fumigatus, } \\
\text { Streptomyces leeuwenhoekii C58 }\end{array}$ & Chaxapeptin, pentalenic acid \\
\hline
\end{tabular}

In another study an established ( 3 day old) culture of marine derived fungus Libertella sp. (CNL-523) was challenged with marine $\alpha$-proteobacterium (CNJ-328) induced biosynthesis of four new primarane diterpenoids- libertellenone A-D which were not produced by these cultures alone. These compounds showed cytotoxicity against HCT-116 human adenocarcinoma cell line and the libertellenone D was more active [11].The cell free supernatant as well as the autoclaved cultures of CNJ-328 
or an ethyl acetate extract of the bacterium failed to induce the accumulation of libertellenones by the fungus Libertella sp. Therefore, a direct physical contact between the cultures is assumed to be necessary for the induction of the libertellenone. Interestingly, the marine bacterial strain $\mathrm{CNJ}-328$ is the same strain that induced pestalone production in the previously mentioned study Table 1.

Emericellamides A and B production were induced by co-culture of marine derived fungus Emericella with marine actinomycete Salinospora arenicola. A 100 fold increase in their production was observed in the co-culture [12]. These compounds showed antibacterial activity against methicillin resistant Staphylocccus aureus (MRSA) and weak cytotoxic effects against HCT-116 cells. Dusane et al. [13] investigated the enhancement or induction of antimicrobial, biosurfactant and quorum sensing inhibition property in marine bacteria due to cross species and cross genera interactions. co- cultivation of marine epibiotic bacteria- Bacillus sp.S3, B. pumilus S8, B. licheniformis D1 and Serratia marcescens V1 from the surface of green mussel, Perna viridis and the coral Symphyllia sp. with pathogenic or biofouling fungi Candida albicans (6A) and Yarrowia lipolytica (YL) and bacteria Pseudomonas aeruginosa (PA) and Bacillus pumilus (B1) showed enhancement or induction in the antimicrobial activity, biosurfactant production and quorum sensing inhibition. This co-culture approach resulted in increased antibacterial activity against PA and B1 and improved biosurfactant production of $B$. pumilus with epibionts $S$. marcescens or with $B$. licheniformis. Coculture of PA with Bacillus species resulted in enhanced quorum sensing inhibition which was evident from reduced pigment production in the indicator strain Chromobacterium violaceum. Thus it became evident that chemical interactions between species in co-culture can influence the secondary metabolite production in the strains.

Marine alga Ulva californica derived isolates of Bacillus $s p$. (B. thuringensis and B. megaterium) were cocultured to yield increased production of indole and (Phe-pro) diketopiperazines which increased antibiotic activity against B. megaterium [14]. Thus the compound production by $B$. thuringensis was a survival strategy for the species which was induced by chemical cues from B. megaterium. This was evident from the co-culture of B. thuringensis with Staphylococcus sciuri from Ulva californica where there was no induction of diketopiperazine accumulation.

A Streptomyces sp. from Panamian tunicate was challenged with Bacillus subtilis, methicillin resistant Staphylococcus aureus (MRSA), methicillin sensitive Staphylococcus aureus (MSSA) and Pseudomonas aeruginosa after coculturing the strain with each of these pathogens [15]. Minimal inhibitory concentrations (MIC) and LC-MS profiles indicated up regulation of antibacterial compounds when Streptomyces sp. cocultured with MRSA. Environmental stress induced by the pathogens promoted the augmented biosynthesis of active antibacterial compound. Cofermentation of Penicillium sp. WC-29-5 with Streptomyces fradiae 007 produced four completely aromatic polyketides- deoxyfunicone; 1, 3, 8-trihydroxy-6- methylxanthen-9-one; (9R, $14 \mathrm{~S})$ - epoxy-11-deoxy funicone and (9S, 14R)-epoxy-11-deoxy funicone [16]. Cytotoxicities of these compounds against HL-60 and H1975 cells have been reported.

Two sponge derived actinomycetes were co-cultured in liquid media- Nocardiopsis sp. RV163 from the Mediterranean sponge Dysidea avara and Actinokinospora sp. EG49 from the Red Sea sponge Spheciospongia vagabhunda yielded several compounds which were detected by LC-PDA and $1 \mathrm{H}-\mathrm{NMR}$ fingerprinting techniques [17]. A study involving interaction between Streptomyces tenjimariensis and 53 unknown marine bacteria for induction of istamycin A and B accumulation by $S$. tenjimariensis showed an enhanced production of istamycins only when it was inoculated $24 \mathrm{~h}$ prior to other bacteria [18]. This shows us the fact that the chemical cues produced at certain critical time period is responsible for enhanced production of the metabolite.

Wakefield et al. [19] reported the dual induction of newly detected fungal and bacterial metabolites by co-culture of marine derived Aspergillus fumigatus MR2012 and two hyper and desert bacteria Streptomyces leeuwenhoekii strain C34 and strain C58. With the strain C34, MR2012 led to production of luteoride D and pseurotin. With C58, chaxapeptin production was augmented and pentalenic acid was first isolated and detected from this strain whereas all the fungal metabolites under axenic culture were suppressed. Here the bilateral crosstalk in the co-fermentation media led to dual induction of metabolite production [20-22].

\section{Conclusion}

Co-culture approach thus serves as an important appproach by which we can increase the yield of bioactive metabolites from marine microbes that are not usually produced under single culture conditions. Induction of natural product biosynthesis in co-culture experiments may be in response to microbial competition. Thus we can estimate that the activation of cryptic gene clusters in microbes in co-culture experiments is a means of survival strategy due to competition or antagonism. In future, this approach will help us to overcome the supply problem and also it will enhance the chemical diversity of bioactive compounds from marine microbes by activating the silent gene clusters.

\section{References}

1. Newman DJ, Cragg GM, Snader KM (2003) Natural products as sources of new drugs over the period 1981-2002. J Nat Prod 66(7): 1022-1087.

2. Newman DJ, Cragg GM (2016) Natural products as sources of new drugs 1981-2014. J Nat Prod 79(3): 629-661.

3. Fenical W, Jensen PR (2006) Developing a new resource for drug discovery: marine actinomycete bacteria. Nat Chem Biol 2(12): 666673.

4. Marmann A, Aly AH, Lin H, Wang B, Proksch P (2014) Co-cultivation-A powerful emerging tool for enhancing the chemical diversity of microorganisms. Mar Drugs12(2): 1043-1065. 
5. Bertrand S, Boni N, Schnee S, Schumpp O, Gindro K, et al. (2014) Metabolite induction via microorganism co-culture: A potential way to enhance chemical diversity for drug discovery. Biotechnol Adv 32(6): 1180-1204

6. Reen FJ, Romano S, Dobson DW, O'Gara F (2015) The sound of silence: Activating silent biosynthetic gene clusters in marine microorganisms. Mar Drugs 13(8): 4754-4783.

7. Netzter T, Fischer J, Webe J, Mattern DJ, Konig CC, et al. (2015) Microbial communication leading to the activation of silent fungal secondary metabolite clusters. Front Microbiol 6: 299.

8. Vigneshwari R, Roopavathi AS, Jayapradhaa R (2015) Co-cultivation - powerful tool for the production of secondary metabolites. J Chem Pharm Res 7(5): 481-485.

9. Haque MU, Haque MA, Sarker AK (2015) Comparative studies of secondary metabolites of co-culture and monoculture of two marine actiomycetes and their biological activities. IJIPSR 3(2): 35-45.

10. Cueto M, Jensen PR, Kauffman C, Fenical W, Lobkovsky E, et al. (2001) Pestalonea new antibiotic produced by a marine fungus in response to bacterial challenge. J Nat Prod 64(11): 1444-1446.

11. Oh DC, Jensen PR, Kauffman CA, Fenical W (2005) Libertellenones A-D: Induction of cytotoxic diterpenoid biosynthesis by marine microbial competition. Bioorg Med Chem 13(17): 5267-5273.

12. Oh DC, Kauffman CA, Jensen PR, Fenical W (2007) Induced production of emericellamides $A$ and $B$ from the marine-derived fungus Emericella sp. in competing co-culture. J Nat Prod 70(4): 515-520.

13. Dusane DH, Matkar P, Venugopalan VP, Kumar AR, Zinjarde SS (2011) Cross-species induction of antimicrobial compounds, biosurfactants and quorum-sensing inhibitors in tropical marine epibiotic bacteria by pathogens and biofouling microorganisms. Curr Microbiol 62(3): 974-980.
14. Trischman JA, Oeffne RE, Luna MGL, Kazaoka M (2004) Competitive induction and enhancement of indole and diketopiperazine in marine bacteria. Marine Biotechnology 6(3): 215-220.

15. Sung AA (2016) Upregulation of antibiotic activity of a Streptomyces sp. via co-culture with challenge pathogens. Honors Scholar theses: 479.

16. Wang Y, Wang L, Zhuang Y, Kong F, Zhang C, et al. (2014) Phenolic polyketides from the co-cultivation of marine-derived Penicillium sp. WC-29-5 and Streptomces fradiae 007. Mar Drugs 12(4): 2079-2088.

17. Dashti Y, Grkovic T, Abdelmohsen VR, Hentscel V, Quinn RJ (2014) Production of induced secondary metabolites by a co-culture of sponge-associated actinomycetes, Actinokineospora sp.EG49 and Nocardiopsis sp. RV163. Mar Drugs 12(5): 3046-359.

18. Slattery M, Rajbhandari I, Wesson K (2001) Competition-mediated antibiotic induction in the marine bacterium Streptomyces tenjimariensis. Microb Ecol 41(2): 90-96.

19. Wakefield J, Hassam HM, Jaepss M, Ebel R, Rateb ME (2017) Dual induction of new Microbial secondary metabolites by fungal-bacterial co-cultivation. Front Microbiol 8: 1284.

20. Bader J, Mart-Geslach, popovic MK, Bajpai R, Stahl U (2010) Relevance of microbial coculture fermentation in biotechnology. J Appl Microbiol 109(2): 371-387.

21. Panjwani L, Deshpande A, Mahajani S, Joshi K (2015) Production of bioactive compounds using marine isolates in co-culturing systems. IJCESR 2(2): 64-68.

22. Lam SK (2007) New aspects of natural products in drug discovery. Trends Microbiol 15(6): 279-289.

\section{Your next submission with Juniper Publishers will reach you the below assets}

- Quality Editorial service

- Swift Peer Review

- Reprints availability

- E-prints Service

- Manuscript Podcast for convenient understanding

- Global attainment for your research

- Manuscript accessibility in different formats ( Pdf, E-pub, Full Text, Audio)

- Unceasing customer service

Track the below URL for one-step submission

https://juniperpublishers.com/online-submission.php 